\title{
Technical note: Validating a dynamometer for noninvasive measuring of udder firmness in dairy cows
}

\author{
S. Bertulat, C. Fischer-Tenhagen, A. Werner, and W. Heuwieser ${ }^{1}$ \\ Clinic for Animal Reproduction, Faculty of Veterinary Medicine, Freie Universität Berlin, Koenigsweg 65, 14163 Berlin, Germany
}

\begin{abstract}
Most measurements of udder pressure are based on devices connected to the gland cistern via cannulas. These devices are either inserted in the teat canal or surgically implanted into the udder tissue. In this study, instead of invasively measuring intramammary udder pressure, we measured the udder firmness noninvasively on the udder surface via a dynamometer. These are commonly used in food research to determine crispiness and firmness of fruits. The objective of this study was to validate a hand-held dynamometer for measuring udder firmness in dairy cows. Specifically we set out to determine inter-investigator repeatability considering potential confounders such as investigator, location, and cow. Through modifications in the standard operating procedure for the measurements, inter-investigator repeatability increased from correlation coefficient $=0.80$ $(\mathrm{n}=275)$ to correlation coefficient $=0.94(\mathrm{n}=634)$. Measurements in different locations within the left hind quarter revealed a firmness gradient from the upper to the lower measuring point. Measurements between the 4 quarters within a cow displayed differences, except between both hind quarters. In $94.8 \%$ of the udders, firmness decreased due to milking. The correlation coefficient, however, between firmness changes and milk yield was low $(\mathrm{r}=0.42, \mathrm{n}=153)$. Our data provide evidence that the dynamometer, although imperfect, does provide a reasonable measure of udder firmness and can be a useful tool in research related to animal health and welfare. However, a standardized operating protocol should be followed to minimize confounding by investigator, location, and quarter.
\end{abstract}

Key words: udder firmness, dynamometer, validation, dairy cow

\section{Technical Note}

Udder pressure in dairy cows has been measured for multiple reasons such as investigating aspects of milk

Received January 23, 2012.

Accepted June 18, 2012.

${ }^{1}$ Corresponding author: w.heuwieser@fu-berlin.de secretion and ejection (Tgetgel, 1926), determining effects of different milking routines (Tucker et al., 2007) or dry-off strategies (Tucker et al., 2009) on udder pressure. Most approaches have been based on measurement of the intramammary pressure using manometers connected via fluid-filled tubes to cannulas either inserted into the teat canal (Mayer et al., 1991) or surgically implanted into the udder tissue (Witzel and McDonald, 1964). These methods provided useful information, but the equipment is cumbersome and has several technical limitations that precluded use in the field. A different approach was adopted in 3 studies (Phillips, 1954; Tucker et al., 2007, 2009) that used spring pressure to measure udder firmness noninvasively on the udder surface instead of an invasive intramammary udder pressure measurement. These previously used devices, however, are not commercially available.

Possible applications of a noninvasive udder pressure measurement are manifold and the determination of udder firmness could be interesting in various areas of research. Palpations scores (Gleeson et al., 2007; O'Driscoll et al., 2011) are an established tool in daily veterinary practice. One application is the diagnosis of mastitis (Nielsen et al., 2004; Wilson et al., 2004).

Manual palpation, however, might be subjective; the technique has never been validated and information about repeatability is not available. A tool potentially facilitating an increased accuracy of mastitis diagnosis and better prediction of treatment outcome might be a valuable improvement.

Most recently, the influence of drying-off dairy cows on their animal well-being was investigated (Odensten et al., 2007; Valizaheh et al., 2008). To evaluate relationships between udder firmness and animal welfare on commercial dairy farms, a noninvasive measuring method would be advantageous.

In plant and food research, pressure measurement devices (i.e., dynamometers) are widely used to control crispiness and firmness of fruits (Feng et al., 2011). The force needed to insert the measuring tip into the fruit flesh is measured with such a device. One of these commercially available hand-held dynamometers (Penefel DFT 14; Agro Technologies, Forges-les-Eaux, France) is designed for free-hand usage, works on batteries, and 
allows a noninvasive measurement (Gamrasni et al., 2010; Sabban-Amin et al., 2011).

The overall objective of this study was to validate the Penefel DFT 14 dynamometer for udder firmness measurement in dairy cows. Specifically, we set out (1) to evaluate the inter-investigator repeatability, (2) to study the effect of location of measurement on firmness, and (3) to examine the relationship between firmness changes before and after milking and milk yield.

The study was conducted between April and August 2011 on a commercial dairy farm in Brandenburg, Germany. Cows were managed according to the guidelines set by the International Cooperation on Harmonization of Technical Requirements for Registration of Veterinary Medicinal Products (Hellmann and Radeloff, 2000). Eighty Holstein-Friesian dairy cows (31 primiparous and 49 multiparous) were included in the study 7 d before drying-off (343 \pm 39 DIM; mean \pm SD) and followed up for $9 \mathrm{~d}$ after drying-off. Cows were housed in a straw-bedded freestall barn and fed a roughage mix delivered twice per day at 0830 and $1700 \mathrm{~h}$. Latelactating cows received (on a DM basis) $54.3 \%$ corn silage, $25.4 \%$ haylage, $16.3 \%$ distillers grains, $0.9 \%$ corn, $0.8 \%$ soy, $2.0 \%$ rapeseed, and $0.3 \%$ basic mineral mix. Dry cows received, on a DM basis, $64.7 \%$ haylage, $32.8 \%$ corn silage, $1.7 \%$ hay, $0.3 \%$ corn, and $0.5 \%$ mineral mix. Concentrate was available for each cow individually via an automatic feeder $(35 \%$ wheat, $35 \%$ rye, $24 \%$ rapeseed extract, $5 \%$ soy, and $1 \%$ oil, on a DM basis). Lactating cows were milked twice daily in a $2 \times 8$ Herringbone milking parlor (Alpro System; DeLaval, Tumba, Sweden) from 0600 to $0900 \mathrm{~h}$ and 1600 to $1900 \mathrm{~h}$.

Before enrollment, udders were palpated and milk was visually examined on a dark surface. One day before dry-off, examinations were repeated and a California mastitis test was performed. Cows with signs indicative of mastitis, udder or teat lesions, alterations of the udder tissue, or less than 4 functional quarters were excluded. Udder examinations were repeated once per week until the cow completed the study. After dryingoff, milk was not examined. Cows were retrospectively withdrawn if any off the signs mentioned above were observed.

The udder firmness was measured using a Penefel DFT 14 dynamometer. The device $($ size $=250 \times 93 \times$ $30 \mathrm{~mm}$; weight $=415 \mathrm{~g}$ ) consists of a pressure sensor with a measuring tip connected to a processing unit and a digital display (Figure 1). The dynamometer measures the maximum weight bearing on the tip in kilograms. The measuring range is 0.05 to $14 \mathrm{~kg}$, with a precision of $\pm 0.04 \mathrm{~kg}$ according to the manufacturer. The output value is the arithmetic mean of a certain number of measurements and their coefficient of varia- tion. According to the manufacturer, the device can be used with a specific support or free hand.

The dynamometer used for this study was equipped with a $15-\mathrm{mm}$ diameter tip. A plastic plate $(70 \times 100$ $\mathrm{mm}) 20 \mathrm{~mm}$ behind and parallel to the surface of the measuring tip was added to standardize the penetration depth of the measuring tip into the udder tissue. The unit was programmed to a threshold of $0.3 \mathrm{~kg}$ and to display mean and coefficient of variation of 5 consecutive measurements. Values with a coefficient of variation exceeding $10 \%$ were discarded and the measurement repeated. All measures were carried out free hand.

Before the actual measurements, 7 investigators were trained to use the dynamometer in the following manner. Based on information gathered from the manufacturer and scientific literature pertaining to measurements of fruits, a draft standard operating procedure (SOP) was written. The 7 investigators conducted the measurements using the draft SOP and when disagreement occurred, they reviewed the definition until agreement was reached. Four experiments were conducted to determine inter-investigator repeatability (experiments 1 and 2), to quantify effects of location within a given quarter and between quarters (experiment 3), and to compare measurements of udder firmness and teat distances before and after milking (experiment 4).

In experiment 1 , the following criteria were added to the SOP. The cow had to stand with all 4 legs on a level surface during the whole measurement. The measuring tip had to be pushed against the surface of the udder at a right angle. Firmness measurements were conducted in the middle of the left hind quarter. In all cases, both investigators used the same dynamometer and recorded the firmness measurements independently within $2 \pm 1$ min. Because inter-investigator repeatability was low, the SOP was modified and a second experiment was conducted.

In experiment 2, the measuring point was marked with an animal marker pen (Raidex GmbH, Dettingen, Germany) in the middle of the left hind quarter to ensure that both investigators conducted the measurement at a consistent location. It was also added to the SOP that all 4 edges of the supporting plate had to touch the udder surface to standardize penetration depth. Furthermore, if the cow had shifted one of her legs before both investigators concluded their measurement, both measurements had to be repeated. In all cases, both investigators used the same dynamometer and recorded the measurements independently within $2 \pm 1$ min.

In experiment 3 , the criteria established in experiment 2 were used. To estimate the effect of the measuring location within a given quarter and between different 


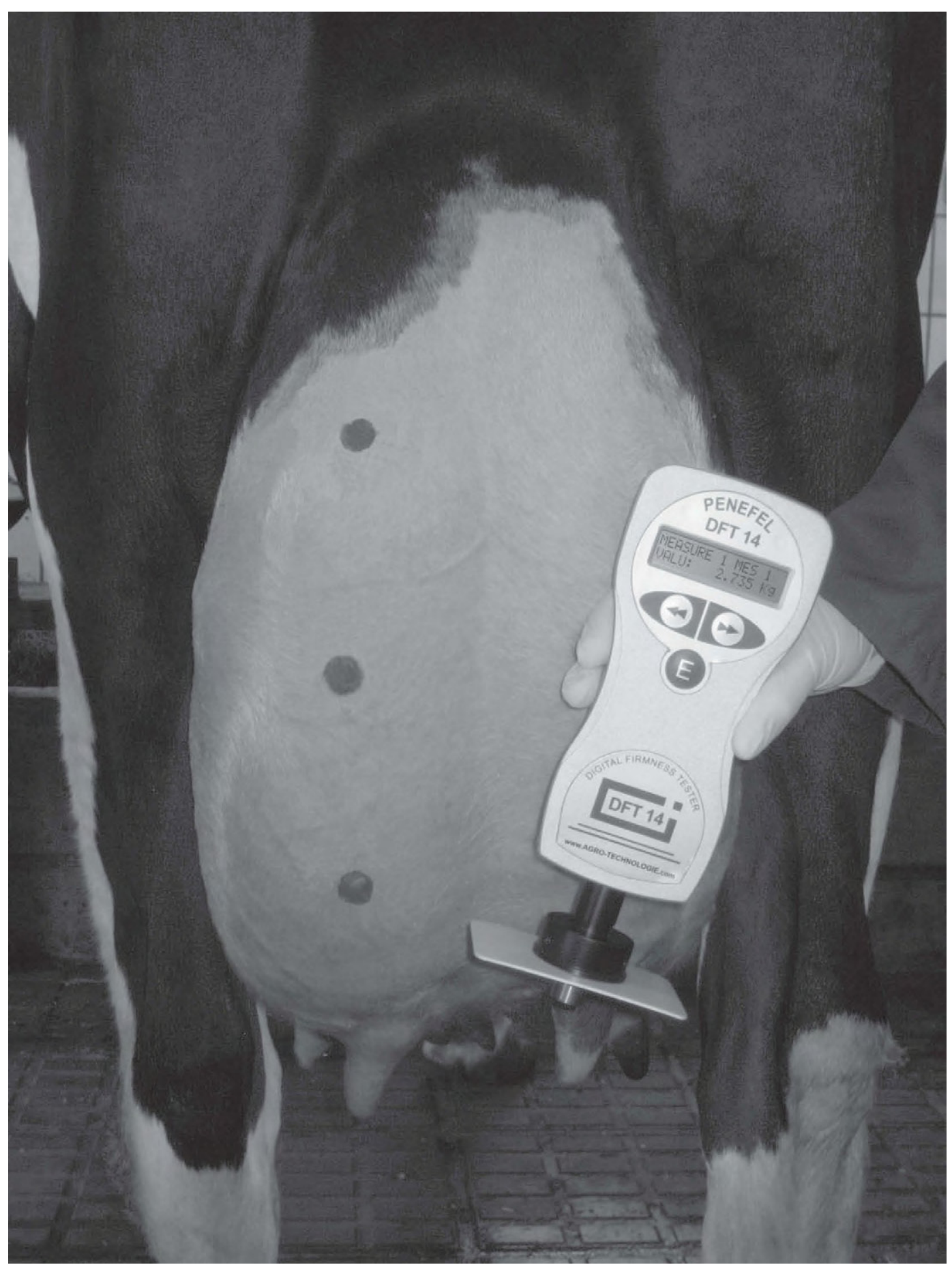

Figure 1. Dynamometer (Penefel DFT 14; Agro Technologies, Forges-les-Eaux, France) and udder with marked measuring points (experiment 3).

quarters within 1 udder, udder firmness was measured in 6 different locations. To determine firmness differences within 1 quarter, 198 measurements each were carried out in the middle, lower, and upper third of the left hind quarter (Figure 1). To study differences in firmness between different quarters, the firmness of each quarter was measured independently, but at the same level in 56 cows. Measuring points were marked with an animal marker pen before measuring started. Firmness measurements were carried out within $2 \pm$ 
1 min by the same investigator using the same dynamometer.

To compare udder firmness and teat distances before and after milking in relationship to milk yield, 80 cows were enrolled in experiment 4 . Both udder firmness and teat distances were measured on $2 \mathrm{~d}$ before and after the evening milking. Measurements of teat distances and udder firmness were conducted by the same 2 independent investigators. The first measurements were conducted in the barn $1 \mathrm{~h} \pm 30 \mathrm{~min}$ before milking, whereas the second measurements were conducted directly after milking in the milking parlor. As in experiment 2 , the measuring point was marked in the middle of the left hind quarter to ensure a consistent location. Teat distances between the front, hind, left, and right teats were determined with a $300-\mathrm{mm}$ sliding caliper (Conrad Electronic SE, Hirschau, Germany). The measuring point was the opening of the teat canal. Values were recorded with an accuracy of $\pm 0.5 \mathrm{~cm}$. The sum of the 4 measured teat distances within an udder was defined as the total teat distance (TTD). All measurements were carried out within $2 \pm 1 \mathrm{~min}$ by the same investigator using the same dynamometer and sliding caliper. Milk yield per cow and milking were recorded in the parlor.

Data were entered into Excel (version 2010; Microsoft Corp., Redmond, WA) and statistical analyses were performed with SPSS for Windows (version 20.0; SPSS Inc., Munich, Germany). The correlation and the difference between 2 investigators before and after marking a measuring point were investigated using Pearson correlation and paired $t$-test, respectively. In experiment 1 and 2, inter-investigator repeatability for an individual pair of investigators was only calculated if a minimum of 30 paired observations were documented. The inter-investigator variation was calculated by dividing the difference between the udder firmness measurements of both investigators $(|\mathrm{F} 2-\mathrm{F} 1|)$ by the firmness measured by investigator 2 (F2; Schirmann et al., 2009). The results were read in percent. The interoperator agreement index (IAI) was calculated as follows: $\mathrm{IAI}=1-\left\{\left(\left|\mathrm{X}_{\mathrm{A}}-\mathrm{X}_{\mathrm{B}}\right|\right) /\left[\left(\mathrm{X}_{\mathrm{A}}+\mathrm{X}_{\mathrm{B}}\right) / 2\right]\right\}$ (van der Vlugt-Meijer et al., 2006; White et al., 2008). Comparison of clinical measurements with a correlation coefficient can be inappropriate. Therefore, the agreement between observers was tested and analyzed with a Bland-Altman plot (Bland and Altman, 1986). The effect of the different investigators on udder firmness values was evaluated in a linear mixed-model ANOVA with repeated measurements. The random effect of cows was included in this model. Moreover, the diagonal covariance structure was used, because it resulted in the model with lowest Akaike information criterion value. Post hoc comparison was performed with the least significant difference test. Comparing the firmness values measured in different locations, the correlation coefficient was determined for each possible combination and a repeated-measures ANOVA was performed. The least significant difference test was used for post hoc comparison. The correlation and differences of TTD between 2 investigators were investigated using Pearson correlation and a paired $t$-test, respectively. The TTD and udder firmness measurements of both investigators were averaged to compare values before milking and after milking. The association between udder firmness, TTD, and milk yield were determined using Pearson correlation. All values reported are least squares means \pm standard error. The significance level was set at $P$ $<0.05$.

Eighty cows were enrolled in the experiments. Nine cows and 1 cow were excluded within the first week because of a positive California mastitis test and 1 case of clinical mastitis, respectively. In total, 2,838 udder firmness measurements were documented.

Three pairs of investigators had more than 30 paired observations in the first and second experiment and were analyzed separately (i.e., pairs A, B, and C). In experiment 1 (275 paired observations), the correlation coefficient was $0.80(P<0.001)$ and the mean deviation $(0.02 \pm 0.21 \mathrm{~kg})$ was not significant $(P=0.15)$. For investigator pairs $\mathrm{A}$ and $\mathrm{B}$, however, the firmness measurements differed (Table 1). The Bland-Altman plot (Figure 2) illustrated a mean disagreement between the investigators close to 0 , indicating good accuracy of the measurements. Greater disagreement was observed for higher means of firmness measurements. The average inter-investigator variation was $20.0 \%$. The IAI for all measurements within experiment 1 averaged $0.81 \pm 0.16$ (Table 1). These results demonstrate that repeatability of the udder firmness measurement as implemented according to the SOP was not sufficient in experiment 1. The linear mixed-model ANOVA proved that the individual pair of investigators had an effect on the level of disagreement between measurements $(P=0.001)$. Additionally, an effect of the number of measurements within 1 cow could be shown $(P=0.008)$, whereas the influence of the individual cow on the disagreement was almost negligible $(P=0.043)$.

A modified SOP was established in experiment 2 to improve the inter-investigator repeatability. The penetration depth and the measuring point were defined and measurements disturbed by movements of the cow were excluded. Because of this last exclusion criterion, $9.3 \%$ of the measurements had to be repeated. As in the first experiment, pairs A, B, and C were analyzed separately. All correlation coefficients increased considerably (Table 1 ). The $t$-test did not demonstrate disagreements for any pair of investigators. The mean 
Table 1. Inter-investigator repeatability in experiment 1 and 2 for 3 pairs of investigators with at least 30 paired observations

\begin{tabular}{|c|c|c|c|c|c|c|c|}
\hline \multirow[b]{2}{*}{ Investigator } & \multirow{2}{*}{$\begin{array}{c}\text { Paired } \\
\text { observations } \\
\text { (no.) }\end{array}$} & \multirow[b]{2}{*}{$\mathrm{r}$} & \multirow[b]{2}{*}{$P$-value } & \multicolumn{2}{|c|}{$\begin{array}{l}\text { Difference of paired } \\
\text { measurements }\end{array}$} & \multirow{2}{*}{$\begin{array}{l}\text { Agreement index } \\
(\text { mean } \pm \mathrm{SD} ; \mathrm{kg})\end{array}$} & \multirow{2}{*}{$\begin{array}{c}\text { Inter-investigator } \\
\text { variation } \\
(\%)\end{array}$} \\
\hline & & & & Mean $\pm \mathrm{SD}(\mathrm{kg})$ & $P$-value & & \\
\hline Pair A & 74 & 0.83 & $<0.001$ & $0.07 \pm 0.17$ & 0.001 & $0.82 \pm 0.15$ & 20.4 \\
\hline Pair B & 36 & 0.80 & $<0.001$ & $-0.12 \pm 0.21$ & 0.002 & $0.76 \pm 0.19$ & 20.5 \\
\hline Pair C & 102 & 0.85 & $<0.001$ & $0.00 \pm 0.20$ & 0.96 & $0.83 \pm 0.15$ & 19.7 \\
\hline Pair B & 76 & 0.94 & $<0.001$ & $0.00 \pm 0.12$ & 0.79 & $0.91 \pm 0.09$ & 9.3 \\
\hline Pair C & 190 & 0.95 & $<0.001$ & $0.00 \pm 0.09$ & 0.77 & $0.88 \pm 0.09$ & 11.6 \\
\hline
\end{tabular}

deviation within pair $\mathrm{A}, \mathrm{B}$, and $\mathrm{C}$ decreased in comparison to experiment 1 (Table 1). Considering all paired observations $(\mathrm{n}=634)$, the correlation improved ( $\mathrm{r}=0.94, P<0.001)$ and the mean deviation decreased $(0.005 \pm 0.12, P=0.323)$ compared with experiment 1. Again, the Bland-Altman plot (Figure 2) illustrated a mean disagreement between the investigators close to 0 . In contrast to experiment 1 , disagreement did not increase with higher firmness and residuals were equally distributed between different firmness values. Overall, the average inter-investigator variation decreased to $11.3 \%$. The mean IAI was $0.89 \pm 0.10$ for all measurements and higher in comparison to experiment 1. Differences between individual pairs of investigators were negligible (Table 1). Compared with experiment 1 , the effects of the individual cow $(P=0.77)$ and the investigators $(P=0.047)$ on the disagreement between both investigators were reduced and can be considered as barely existent. The effect of the number of measurements performed on a given cow did not change $(P=$
0.008) after modifying the SOP. The decreased effect of the investigator can be explained with the standardization of the penetration depth. We assume that the effect of the number of measurements was caused by a familiarization of the cow with the measuring procedure and, therefore, cannot be influenced by procedural changes as implemented between experiment 1 and 2 . In conclusion, udder firmness measurement using the Penefel DFT 14 can be conducted with high interinvestigator repeatability following the experimental design of experiment 2. Previous studies also using an extramammary udder firmness measurement (Phillips, 1954; Tucker et al., 2007, 2009) did not validate the measuring device or controlled the repeatability of measurements. An SOP was not provided in those previous studies; however, Tucker et al. (2007, 2009) described a marking of the measuring point and defined the penetration depth of their device.

Experiment 3 was carried out to determine firmness gradients within the left hind quarter. Firmness differed
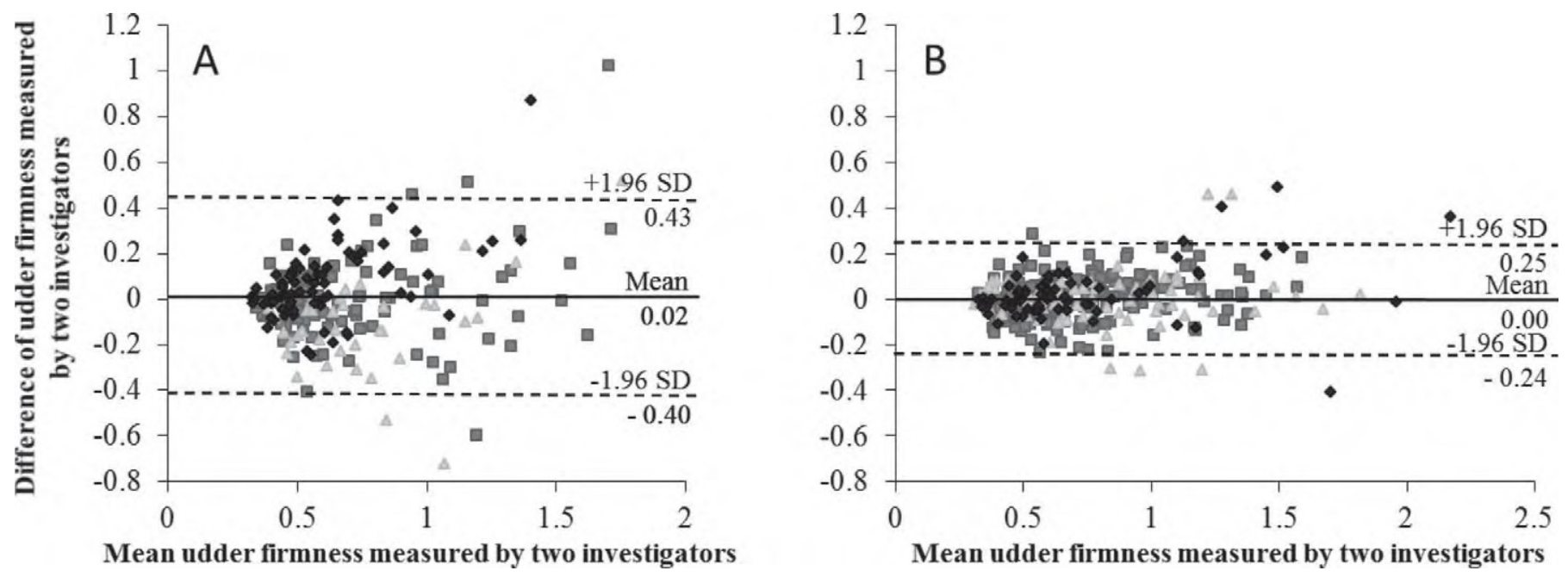

Figure 2. Differences between udder firmness measured by 2 investigators versus the mean of both measurements (in $\mathrm{kg}$ ). Data are shown for experiment 1 (A) and experiment 2 (B) and are divided according to the pair of investigators (pair A, $\mathbf{\square}$; pair B, $\bullet$; pair C, $\mathbf{\Delta}$ ). 
between the 3 locations $(\mathrm{n}=196, P<0.001)$. Average firmness of the upper and lower measuring point was $15.5 \%$ lower $(0.69 \pm 0.29 \mathrm{~kg})$ and $21.1 \%$ higher $(1.01 \pm$ $0.52 \mathrm{~kg}$ ) compared with values measured at the middle measuring point $(0.86 \pm 0.39 \mathrm{~kg})$. The correlation coefficients varied from 0.52 (lower to upper measuring point, $P<0.001$ ) to 0.69 (middle to lower measuring point, $P<0.001)$. One explanation for the pressure distribution within a quarter is Pascal's law, which proves that, in fluids, firmness is highest at the lowest level. We also assume that factors such as distension of the udder tissue, the shape of ligaments, or alterations of the tissue influence the firmness of the udder. Regardless of the reasons, our data emphasize the importance of a defined measuring point for a repeatable measurement as described by Tucker et al. (2007). In the second part of experiment 3, all 4 quarters were measured at the same level. Firmness values differed significantly $(P$ $<0.05)$, except between the hind quarters $(P=0.234)$. Firmness values within both front quarters were lower than in the 2 hind quarters $(P<0.001)$. The correlation coefficients varied between 0.632 (left hind to right front quarter, $P<0.001$ ) and 0.81 (right to left front quarter, $P<0.001)$. This is in agreement with older findings on milk yield and intramammary udder pressure (Kitts et al., 1963; Graf and Lawson, 1968). Both studies found that intramammary pressures measured in the hind quarters were higher compared with the front quarters. According to Lawson and Graf (1968), udder pressure was $18 \%$ higher in the hind quarters, which is similar to our firmness data $(16 \%)$. It is well known that milk yield of the hind quarters is also higher compared with the front quarters (Tančin et al., 2006). Therefore, a relationship between pressure (firmness) and difference in milk yield between front and hind quarters is plausible. According to hydrostatic principles, a higher volume of fluid causes a higher pressure on the wall of an elastic body. To achieve comparable firmness values, measurements should be carried out at the same quarter and at the same level. Implementation of an exact SOP is recommended.

In experiment 4, udder firmness and distances between teats were measured before and after milking by 2 independent investigators and related to milk yield. The inter-investigator repeatability for the TTD measurements was assessed first. The correlation coefficient was $0.98(\mathrm{n}=307, P<0.001)$ and the mean difference between the TTD measured by 2 investigators was $0.06 \pm 2.12 \mathrm{~cm}(P=0.62)$. In $96.1 \%$ of all measurements, differences of TTD were $4 \mathrm{~cm}$ or less. Overall, inter-investigator repeatability for the TTD was excellent $(\mathrm{IAI}=0.96 \pm 0.04)$ and an independence of TTD and investigator was demonstrated. Comparing values before and after milking, both, firmness and
TTD decreased in $91.5 \%$ of the udders. Mean TTD before milking was $42.6 \pm 9.4 \mathrm{~cm}$ and after milking 35.2 $\pm 8.7 \mathrm{~cm}$ (i.e., a $17.6 \%$ decrease). In comparison the firmness decreased from $0.89 \pm 0.32 \mathrm{~kg}$ before to 0.52 $\pm 0.15 \mathrm{~kg}$ after milking (i.e., a $36.5 \%$ decrease). This observation differs considerably from previous studies (Graf and Lawson, 1968), demonstrating a decrease in pressure from $34.3 \pm 0.86 \mathrm{~mm}$ of $\mathrm{Hg}$ before to $3.1 \pm$ $0.27 \mathrm{~mm}$ of $\mathrm{Hg}$ after milking (i.e., a $91 \%$ decrease). This disagreement can be explained by the different methods used. Whereas we used a dynamometer and measured from the outside, Graf and Lawson (1968) cannulated the udder and measured an intramammary pressure. It is plausible that after milking intramammary pressure decreases to almost zero, as no fluid is in the mammary gland. With a dynamometer, however, udder firmness as a function of the tissue firmness and the amount of milk within the udder is being measured. A direct comparison of absolute values with previous studies (Tucker et al., 2007, 2009) also measuring the force required to indent the udder tissue is not meaningful because of different diameters of the tips.

The relationship between firmness change and milk yield $(\mathrm{r}=0.42, P<0.001)$ demonstrated in our experiment is consistent with the results described in the study mentioned above $(\mathrm{r}=0.52, P<0.01)$. Furthermore, relationships existed between milk yield and TTD changes from before to after milking $(\mathrm{r}=0.54$, $P<0.001)$ and between firmness and TTD changes $(\mathrm{r}$ $=0.39, \mathrm{n}=153, P<0.001)$ from before to after milking, respectively. Despite these significant relationships the predictive value of udder firmness or TTD for milk yield is limited. Comparing firmness values of the same udder at different times, higher firmness indicates a larger filling of the udder and a greater time span to the last milking. This substantiates the importance of measuring udder firmness every day at the same time.

Our data provide evidence that the dynamometer, although imperfect, is a valuable device to measure udder firmness. Inter-investigator repeatability is high when an SOP is implemented to minimize the influence of potential confounders such as investigator, location, and cow. It is recommended to carry out measurements at the same quarter and the same level with a marked measuring point and defined penetration depth. Measurements should be taken at the same time after milking to compare firmness values of different days.

The relationship between extramammary udder firmness and intramammary udder pressure remains unclear and warrants further studies to understand how udder firmness reflects pressure conditions inside the udder. Nevertheless, a dynamometer can be useful in research and commercial applications. Relevant research questions that could benefit from such a tool include rela- 
tionships between udder firmness and pain, prevalence of edema, inflammation-mediated alterations in the tissue, or prevalence of milk leakage after dry-off.

\section{ACKNOWLEDGMENTS}

We thank the staff of the Clinic of Animal Reproduction, Freie Universität Berlin (Berlin, Germany) and the dairy farm for their superb cooperation. S. Bertulat was funded in part by a scholarship from Tiergyn Berlin e.V. We are also grateful to Naomi Isaka and Audrey Deflandre Ceva Santé Animale (Libourne, France) for the valuable scientific support and for providing the dynamometer.

\section{REFERENCES}

Bland, J. M., and D. G. Altman. 1986. Statistical methods for assessing agreement between two methods of clinical measurement. Lancet 1:307-310.

Feng, J., A. McGlone, D. Tanner, A. White, S. Olsson, M. Petley, and I. Woolf. 2011. Effect of penetration speed on flesh firmness measured on stored kiwifruit. Postharvest Biol. Technol. 61:29-34.

Gamrasni, D., R. Ben-Arie, and M. Goldway. 2010. 1-Methylcyclopropene (1-MCP) application to Spadona pears at different stages of ripening to maximize fruit quality after storage. Postharvest Biol. Technol. 58:104-112.

Gleeson, D. E., B. O'Brien, L. Boyle, and B. Earley. 2007. Effect of milking frequency and nutritional level on aspects of the health and welfare of dairy cows. Animal 1:125-132.

Graf, G. C., and D. M. Lawson. 1968. Factors affecting intramammary pressures. J. Dairy Sci. 51:1672-1675.

Hellmann, K., and I. Radeloff. 2000. International Cooperation on Harmonization of Technical Requirements for Registration of Veterinary Medicinal Products. VICH, Brussels, Belgium.

Kitts, W. D., M. Merriman, and M. C. Berry. 1963. Studies on the intramammary pressure of dairy cows. Can. J. Anim. Sci. 43:47-55.

Lawson, D. M., and G. C. Graf. 1968. Plasma oxytocic activity and intramammary pressure in lactating dairy cows. J. Dairy Sci. 51:1676-1679.

Mayer, H., R. Bruckmaier, and D. Schams. 1991. Lactational changes in oxytocin release, intramammary pressure and milking characteristics in dairy cows. J. Dairy Res. 58:159-169.

Nielsen, B. H., S. Jacobsen, P. H. Andersen, T. A. Niewold, and P. M. Heegaard. 2004. Acute phase protein concentrations in serum and milk from healthy cows, cows with clinical mastitis and cows with extramammary inflammatory conditions. Vet. Rec. 154:361-365.

Odensten, M. O., B. Berglund, K. P. Waller, and K. Holtenius. 2007. Metabolism and udder health at dry-off in cows of different breeds and production levels. J. Dairy Sci. 90:1417-1428.

O'Driscoll, K., D. Gleeson, B. O'Brien, and L. Boyle. 2011. Does omission of a regular milking event affect cow comfort? Livest. Sci. 138:132-143.

Phillips, D. S. M. 1954. A recording tympanometer for the measurement of intramammary pressure in the cow. J. Dairy Res. 21:178182.

Sabban-Amin, R., O. Feygenberg, E. Belausov, and E. Pesis. 2011. Low oxygen and 1-MCP pretreatments delay superficial scald development by reducing reactive oxygen species (ROS) accumulation in stored 'Granny Smith' apples. Postharvest Biol. Technol. 62:295-304.

Schirmann, K., M. A. G. von Keyserlingk, D. M. Weary, D. M. Veira, and W. Heuwieser. 2009. Technical note: Validation of a system for monitoring rumination in dairy cows. J. Dairy Sci. 92:6052-6055.

Tančin, V., B. Ipema, P. Hogewerf, and J. Mačuhová. 2006. Sources of variation in milk flow characteristics at udder and quarter levels. J. Dairy Sci. 89:978-988.

Tgetgel, B. 1926. Untersuchung über den Sekretionsdruck und über das Einschiessen der Milch im Euter des Rindes. Schweiz. Arch. Tierheilkd. 68:335-348.

Tucker, C. B., D. E. Dalley, J. L. K. Burke, and D. A. Clark. 2007. Milking cows once daily influences behavior and udder firmness at peak and mid lactation. J. Dairy Sci. 90:1692-1703.

Tucker, C. B., S. J. Lacy-Hulbert, and J. R. Webster. 2009. Effect of milking frequency and feeding level before and after dry off on dairy cattle behavior and udder characteristics. J. Dairy Sci. 92:3194-3203.

Valizaheh, R., D. M. Veira, and M. A. G. von Keyserlingk. 2008. Behavioural responses by dairy cows provided two hays of contrasting quality at dry-off. Appl. Anim. Behav. Sci. 109:190-200.

van der Vlugt-Meijer, R. H., B. P. Meij, and G. Voorhout. 2006. Intraobserver and interobserver agreement, reproducibility, and accuracy of computed tomographic measurements of pituitary gland dimensions in healthy dogs. Am. J. Vet. Res. 67:1750-1755.

White, J. M., D. J. Mellor, M. Duz, C. J. Lischer, and L. C. Voute. 2008. Diagnostic accuracy of digital photography and image analysis for the measurement of foot conformation in the horse. Equine Vet. J. 40:623-628.

Wilson, D. J., R. N. González, J. Hertl, H. F. Schulte, G. J. Bennett Y. H. Schukken, and Y. T. Gröhn. 2004. Effect of clinical mastitis on the lactation curve: A mixed model estimation using daily milk weights. J. Dairy Sci. 87:2073-2084.

Witzel, D. A., and J. S. McDonald. 1964. Bovine intramammary pressure changes during mechanical milking. J. Dairy Sci. 47:13781381 . 